\title{
Low alfentanil target-concentrations improve hemodynamic and intubating conditions during induction with sevoflurane
}

\author{
[De faibles concentrations cibles d'alfentanil améliorent l'hémodynamique et les \\ conditions d'intubation pendant l'induction avec du sépoflurane]
}

Nathalie Nathan MD PhD, ${ }^{*}$ David Vandroux MD, ${ }^{*}$ Mohammed Benrhaiem MD, ${ }^{*}$ Pierre Marquet MD PhD, $\dagger$ Pierre-Marie Preux MD PhD $\ddagger$ Pierre Feiss MD*

Purpose: To investigate the effects of different alfentanil target-concentrations on hemodynamics, respiration and conditions of tracheal intubation during an inhalation induction with $8 \%$ sevoflurane.

Methods: In this prospective randomized open-label study, 40 ASA I adult patients received alfentanil at the following target-concentrations: zero (Group 0), 25 (Group 25), 50 (Group 50) and 75 $\mathrm{ng} \cdot \mathrm{mL}^{-1}$ (Group 75), starting five minutes before induction of anesthesia with $8 \%$ sevoflurane in $50 \%$ nitrous oxide. The ease of intubation was determined on fixed criteria and scored; arterial pressure, heart rate and bispectral index (BIS) were recorded at one-minute intervals.

Results: Times to allow tracheal intubation were shortened only in Group 75 (94 $\pm 8 \mathrm{sec}$ ) as compared to Group 0 (| $40 \pm$ I I sec, $P<0.05)$. BIS values, tracheal intubation scores and number of attempts were not different between groups. However, more patients suffered from apnea in Group 75. Heart rate and mean arterial pressure remained stable in Group 75 whereas they increased significantly in the three other groups. No patient suffered hypotension.

Conclusion: Adding alfentanil at a $75 \mathrm{ng} \cdot \mathrm{mL}^{-1}$ target-concentration during an inhalation induction with $8 \%$ sevoflurane in $50 \%$ nitrous oxide allows intubation slightly earlier and provides stable hemodynamic conditions but the incidence of apnea during induction is higher. Lower concentrations are of little clinical interest.
Objectif : Rechercher les effets de différentes concentrations cibles d'alfentanil sur l'hémodynamique, la respiration et les conditions d'intubation endotrachéale pendant l'induction par inhalation de sévoflurane à $8 \%$.

Méthode : L'étude prospective, randomisée et ouverte comportait 40 patients adultes d'état physique ASA I recevant de l'alfentanil selon les concentrations cibles suivantes : zéro (Groupe 0), 25 (Groupe 25), 50 (Groupe 50) et $75 \mathrm{ng} \cdot \mathrm{mL}^{-1}$ (Groupe 75), cinq minutes avant l'induction de l'anesthésie avec du sévoflurane à $8 \%$ dans $50 \%$ de protoxyde d'azote. La facilité d'intubation a été évaluée d'après des critères fixes, et cotée; la tension artérielle, la fréquence cardiaque et l'index bispectral (B/S) ont été notés à intervalles d'une minute.

Résultats : L'intervalle précédant l'intubation endotrachéale a été plus court dans le Groupe 75 (94 $\pm 8 \mathrm{sec}$ ) comparé au Groupe 0 ( $40 \pm 1 / \mathrm{sec}, P<0,05)$. Les valeurs de BIS, les scores à l'intubation et le nombre d'essais nécessaires n'ont pas présenté de différence intergroupe. Plus de patients ont souffert d'apnée dans le Groupe 75. La fréquence cardiaque et la tension artérielle moyenne sont demeurées stables dans le Groupe 75, mais ont augmenté significativement dans les trois autres groupes. Aucun patient n'a présenté d'hypotension.

Conclusion : L'ajout d'alfentanil selon une concentration cible de 75 $\mathrm{ng} \cdot \mathrm{mL}^{-1}$ pendant l'induction de l'anesthésie, par inhalation de sévoflurane à $8 \%$ dans $50 \%$ de protoxyde d'azote, permet d'intuber un peu plus tôt et fournit des conditions hémodynamiques stables, mais augmente l'incidence d'apnée pendant l'induction. Les concentrations plus faibles sont sans intérêt clinique.

From the Departments of Anesthesia, ${ }^{*}$ and Pharmacology, $†$ CHU Dupuytren; and the Department of Biostatistics, $\ddagger$ Faculty of Medicine, Hôpital du Cluzeau, Limoges, France. Address correspondence to: Dr. N. Nathan, Department of Anesthesia, CHU Dupuytren, 2 ave Martin Luther King, 87042 Limoges,

France. Phone: 33-555-05-67-91; Fax: 33-555-05-67-92; E-mail: nathan@unilim.fr Accepted for publication February 27, 2003.

Revision accepted August 19, 2003.

Final revision accepted November 28, 2003. 
I NHALATION induction with sevoflurane is gaining popularity in adults, because tracheal intubation may be performed without muscle relaxants, spontaneous ventilation is better maintained than after an $i v$ induction and loss of consciousness is as rapid. ${ }^{1,2}$ However, because heart rate may be severely increased, inhalation induction carries the risk of myocardial ischemia in patients at risk. ${ }^{3-5}$ Furthermore, time to tracheal intubation or laryngeal mask insertion is delayed. ${ }^{1,6}$ Because opioids decrease sevoflurane minimum alveolar concentration (MAC) and heart rate, they may reduce hemodynamic changes and time to tracheal intubation. ${ }^{7-10}$ However asystole or severe hypotension may occur, probably because of inappropriate opioid dosing, and the effects of sevoflurane-alfentanil on the ease and speed of tracheal intubation have not been evaluated..$^{9,11-13}$ Our study aimed to determine the dose of alfentanil required to decrease the time to tracheal intubation and blunt the increase in heart rate associated with an inhalation induction.

\section{Methods}

After Ethical Committee approval and written informed consent, 40 adult ASA physical status I patients were included in this prospective open-label randomized study. At the time of inclusion, patients were instructed on how to perform vital capacity breathing. Two hours before surgery they received 1 $\mathrm{mg} \cdot \mathrm{kg}^{-1}$ hydroxyzine. All patients were monitored with an electrocardiogram, pulse oximeter, non-invasive blood pressure device, and bispectral index (BIS; frontal montage, Aspect-1000, Aspect Medical System Inc., Framingham, MA, USA). According to the computerized randomization displayed in sealed envelopes, patients received during the five-minute preceding sevoflurane inhalation, one of the four following alfentanil plasma target-concentrations (Scott weight-adjusted pharmacokinetics model, Stanpump): $0 \mathrm{ng} \cdot \mathrm{mL}^{-1}$ (Group 0), $25 \mathrm{ng} \cdot \mathrm{mL}^{-1}$ (Group 25), 50 $\mathrm{ng} \cdot \mathrm{mL}^{-1}$ (Group 50) and $75 \mathrm{ng} \cdot \mathrm{mL}^{-1}$ (Group 75). During this five-minute period, patients received oxygen $8 \mathrm{~L} \cdot \mathrm{min}^{-1}$ through a facemask. This five-minute period equals five times the alfentanil blood-brain equilibration half-life, which permits equilibrium of alfentanil concentration between blood and brain. Anesthesia was then induced by asking the patient to perform a vital capacity through a face mask connected to a circle system pre-filled with $8 \%$ sevoflurane in $50 \% \mathrm{~N}_{2} \mathrm{O}$ at a $12 \mathrm{~L} \cdot \mathrm{min}^{-1}$ fresh gas flow. Patients were asked to repeat the vital capacity whenever necessary. Time to loss of eyelash reflex and drop of a pen held in the right hand were measured. Tracheal intubation was attempted as soon as the following criteria were obtained: loss of consciousness, mandibular relaxation allowing the insertion of an oropharyngeal airway, BIS $<60$ and when the patient tolerated two manual lung inflations. Time to obtain all these criteria defined the theoretical delay to intubation. The number of attempts at tracheal intubation and time to completion were noted for all patients. The conditions of tracheal intubation were graded according to fixed criteria (Table I). Rocuronium bromide $0.6 \mathrm{mg} \cdot \mathrm{kg}^{-1}$ was injected if one of the following events occurred: apnea and inability to ventilate the patient, laryngospasm or closed vocal cords at time of intubation, cough severe enough to induce hypoxemia $\left(\mathrm{SpO}_{2}<\right.$ 93\%). Heart rate, blood pressure, $\mathrm{SpO}_{2}$, BIS values, respiratory rate and end-tidal sevoflurane concentrations were recorded before and each minute following the beginning of the alfentanil infusion and until the fifth minute following tracheal intubation. Immediately after tracheal intubation, $5 \mathrm{~mL}$ of venous blood were collected to measure serum alfentanil concentration by gas chromatography- mass spectrometry (lower limit of detection: $5-10 \mathrm{ng} \cdot \mathrm{mL}^{-1}$, linearity range: $\left.10-500 \mathrm{ng} \cdot \mathrm{mL}^{-1}\right)$.

Assuming a (3.7-5.7) min confidence interval for time to intubation without alfentanil, a sample size of ten patients per group can demonstrate by two twotailed t tests with an $\alpha$ error of 0.05 and a $B$ error of 0.80 , a $1.3 \mathrm{~min}$ decrease in time to tracheal intubation in one group receiving alfentanil. 6 Data are presented as mean \pm SD. Differences vs baseline values were used to compare hemodynamic data. Data were compared by ANOVA followed by $t$ tests when normally distributed ( $P>0.05$ by Bartlett tests) or Mann Whitney $U$ tests otherwise. A Bonferroni correction was used for $t$ tests when ANOVA was not significant. Qualitative data were compared using exact Fisher tests for multiple groups.

\section{Results}

Demographic data were normally distributed and not different between groups (Table II). Time to loss of eyelash reflex, to drop a pen and to obtain a BIS $<60$ were not influenced by any of the alfentanil concentrations. However criteria for tracheal intubation were reached and intubation performed earlier in patients receiving the highest alfentanil target-concentration (Table III). Once criteria were reached, tracheal intubation was achieved at a similar speed and after a similar number of attempts in the four groups (Tables III and IV). During laryngoscopy, mandible relaxation was rated excellent in all patients whether they received or not an opioid. However, in 5/10 patients 
TABLE I Tracheal intubation score

\begin{tabular}{llll}
\hline Scores & 0 & 1 & 2 \\
\hline Mandibular relaxation & Trismus & Intermediate & Complete \\
Glottic opening & Closed & Intermediate & Opened \\
Vocal cord mobility & Mobile & Immobile & --- \\
Cough & $\begin{array}{l}\text { Severe }(>3) \text { with } \\
\text { movement of }\end{array}$ & Moderate $<3$ & None \\
& the four limbs & \\
& & & \\
\hline
\end{tabular}

TABLE II Demographic data

\begin{tabular}{lllll}
\hline & Group 0 & Group 25 & Group 50 & Group 75 \\
\hline Age & $38(9)$ & $31(9)$ & $38(9)$ & $38(12)$ \\
Weight & $69(15)$ & $65(12)$ & $67(9)$ & $69(15)$ \\
Height & $169(6)$ & $171(9)$ & $165(6)$ & $171(9)$ \\
\hline
\end{tabular}

Mean (SD).

TABLE III Times to loss of eyelash reflex (LOER), drop of a pen, bispectral index (BIS) $<60$, attempt of tracheal intubation (TI allowed) and completion of intubation (end TI); difference between TI allowed and end TI (diff TI) and alfentanil concentration in venous blood after tracheal intubation

\begin{tabular}{lllll}
\hline & Group 0 & Group 25 & Group 50 & Group 75 \\
\hline LOER (sec) & $39(12)$ & $47(24)$ & $40(12)$ & $42(21)$ \\
Drop of pen (sec) & $50(15)$ & $78(24)^{*}$ & $56(15)$ & $56(24)$ \\
BIS < 60 (sec) & $133(36)$ & $138(36)$ & $124(39)$ & $109(27)^{*}$ \\
TI allowed (sec) & $140(33)$ & $113(39)^{*}$ & $135(51)$ & $94(24)^{*}$ \\
End of TI (sec) & $206(48)$ & $215(108)$ & $201(51)$ & $167(54)^{*}$ \\
Diff TI (sec) & $56(60)$ & $102(99)$ & $96(39)$ & $73(45)$ \\
Alfentanil & N/A & $12.1(6.9)$ & $24.9(11.1)$ & $51.7(13.5)$ \\
concentration & & & & \\
(ng.mL mL $\left.^{-1}\right)$ & & & & \\
\hline
\end{tabular}

Mean \pm SD. ${ }^{*} P<0.05$ as compared to group $0 . \mathrm{N} / \mathrm{A}=$ not applicable.

TABLE IV Characteristics of tracheal intubation

\begin{tabular}{lllll}
\hline Scores & Group 0 & Group25 & Group 50 & Group 75 \\
\hline $\begin{array}{l}\text { Mandibular relaxation 0/0/10 } \\
\text { score 1/2/3 }\end{array}$ & $0 / 0 / 10$ & $0 / 0 / 10$ & $0 / 0 / 10$ \\
$\begin{array}{l}\text { Glottic opening } \\
\text { score 0/1/2 }\end{array}$ & $0 / 0 / 10$ & $0 / 0 / 10$ & $0 / 0 / 10$ & $1 / 4 / 5$ \\
$\begin{array}{l}\text { Vocal cord mobility } \\
\text { score 0/1 }\end{array}$ & $1 / 9$ & $0 / 10$ & $2 / 8$ & $1 / 9$ \\
$\begin{array}{l}\text { Cough at intubation } \\
\text { score 0/1/2 }\end{array}$ & $3 / 4 / 3$ & $3 / 3 / 4$ & $1 / 7 / 2$ & $2 / 5 / 3$ \\
$\begin{array}{l}\text { Total score } \\
\text { Apnea }>\text { two minutes }\end{array}$ & $5.9(0.3)$ & $6.1(0.3)$ & $5.9(0.2)$ & $5.4(0.4)$ \\
$\begin{array}{l}\text { Attempts at tracheal } \\
\text { intubation } 1 / 2 / 3\end{array}$ & $7 / 3 / 0$ & $8 / 0 / 2$ & $7 / 2 / 1$ & $7 / 3 / 0$ \\
Rocuronium & $n=1$ & $n=0$ & $n=0$ & $n=3$ \\
\hline
\end{tabular}

\section{a-Heart rate variations from baseline}

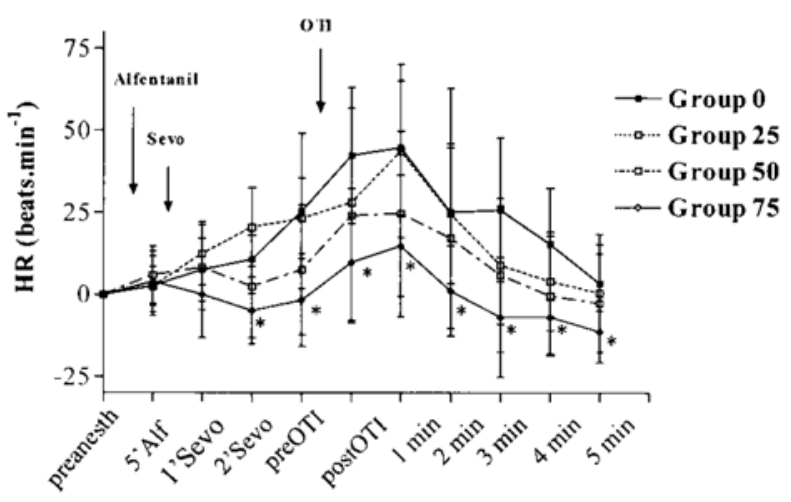

b-Mean arterial pressure variations from baseline

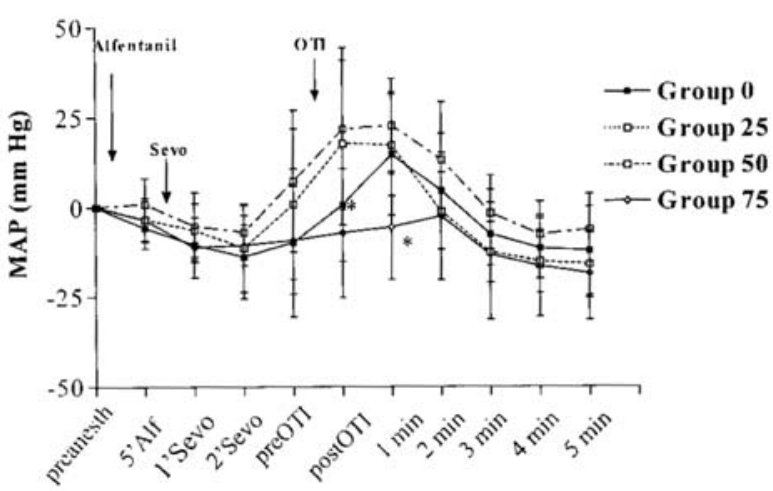

FIGURE 1 Heart rate (beats. min $^{-1}$; Figure la) and mean arterial pressure ( $\mathrm{mmHg}$; Figure $\mathrm{lb}$ ) variations from baseline. Mean $\pm \mathrm{SD}$. ${ }^{*} P<0.05$ as compared to control group. Pre-anesth $=$ before anesthesia; $5^{\prime}$ alf $=$ five minutes after the beginning of alfentanil infusion; l' sevo and 5' sevo = one minute and five minutes after the beginning of sevoflurane inhalation; pre OTI and post OTI = immediately before and after tracheal intubation; $1 \mathrm{~min}$ to $5 \mathrm{~min}=$ one minute to five minutes after tracheal intubation.

receiving the highest alfentanil concentration, vocal cord opening was not optimal and/or apnea lasted more than two minutes. Whatever the target-concentration, alfentanil was unable to suppress the cough reflex following tracheal intubation or cuff inflation (Table IV).

As compared to baseline, variations of heart rate were significant one minute after the beginning of sevoflurane induction in patients receiving either no opioids or a $25 \mathrm{ng} \cdot \mathrm{mL}^{-1}$ alfentanil concentration whereas heart rate remained unchanged in the two 


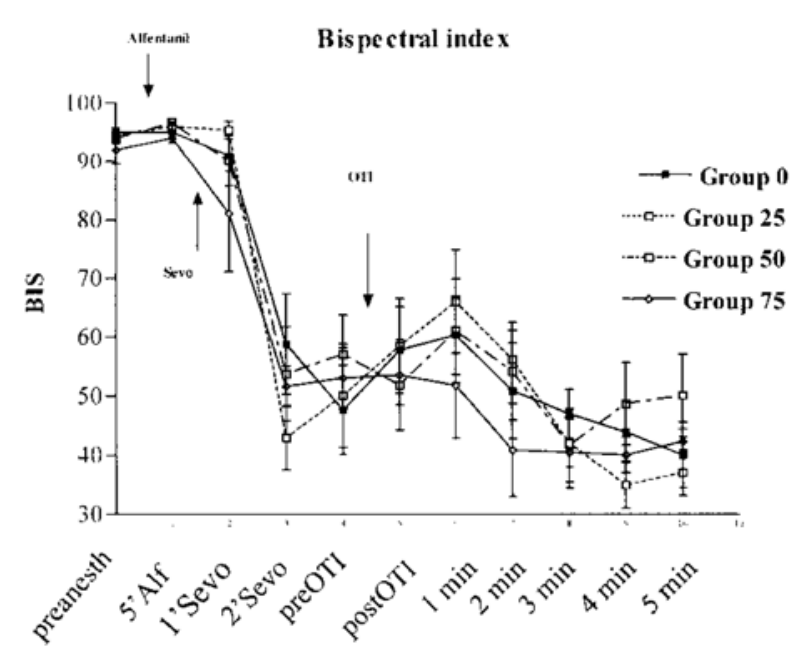

FIGURE 2 Bispectral index (BIS). Pre-anesth = before anesthesia; 5' alf = five minutes after the beginning of alfentanil infusion; 1 ' sevo and 5' sevo = one minute and five minutes after the beginning of sevoflurane inhalation; pre OTI and post OTI = immediately before and after tracheal intubation; $1 \mathrm{~min}$ to $5 \mathrm{~min}=$ one minute to five minutes after tracheal intubation.

other groups (Figure la). Before tracheal intubation, heart rate variations reached $25.4 \pm 7.9 \mathrm{~min}^{-1}$ in the control group, $23.1 \pm 4.1 \mathrm{~min}^{-1}$ in Group $25(P>$ 0.05 as compared to Group 0), $7.5 \pm 6.7 \mathrm{~min}^{-1}$ in Group $50(P=0.08$ vs Group 0$)$ and $-1.8 \pm 4.7 \mathrm{~min}^{-1}$ in Group $75(P=0.005 v s$ Group 0$)$. Immediately and one minute after tracheal intubation, heart rate increased significantly $v s$ baseline in all groups except in patients receiving the $75 \mathrm{ng} \cdot \mathrm{mL}^{-1}$ alfentanil targetconcentration. In these latter patients, heart rate remained stable thereafter and significantly lower than in Group 0 (Figure la).

At the beginning of sevoflurane inhalation, mean arterial pressure differences $v s$ baseline were significant in all groups, without any difference between them (Figure $1 \mathrm{~b}$ ). Immediately after tracheal intubation, the mean arterial pressure increase was significant in all patients except in those receiving $75 \mathrm{ng} \cdot \mathrm{mL}^{-1}$ alfentanil plasma-target-concentration. In these patients, arterial pressure remained stable until the fourth minute following tracheal intubation (Figure lb). The systolic and diastolic arterial pressure variations were similar to those observed for mean arterial pressure (not shown). No decrease in arterial pressure or heart rate higher than $30 \%$ of preanesthetic values were observed. However 8/10 patients of Group 0, 9/10 of Group 25, 6/10 of Group 50 and 4/10 of Group 75 increased their heart rate or arterial pressure above $30 \%$ of baseline. In Group 75, this increase, only observed after tracheal intubation, was always brief. BIS values are reported in Figure 2 and alfentanil concentrations in Table III.

\section{Discussion}

Our study shows that a $75 \mathrm{ng} \cdot \mathrm{mL}^{-1}$ plasma target-concentration of alfentanil is able to blunt the tachycardia observed during an inhalation induction with sevoflurane and following tracheal intubation. Whereas the increase in heart rate is of little consequence in young ASA class I patients, it may be deleterious in older and cardiovascular disabled patients. ${ }^{4}$ This study confirms the clinical synergy between low dose alfentanil and sevoflurane. Dahan et al. demonstrated that maximum synergy between sevoflurane and alfentanil on heart rate occurs at an alfentanil plasma concentration as low as $\mathbf{5 0}$ ng. $\mathrm{mL}^{-1} \cdot{ }^{10}$ In the present study, this alfentanil concentration was measured in patients receiving the 75 $\mathrm{ng} \cdot \mathrm{mL}^{-1}$ target-concentration. Our results suggest that a higher alfentanil concentration is not required to blunt the increase in heart rate related to high sevoflurane concentrations or tracheal intubation.

Our study shows that the addition of alfentanil 75 $\mathrm{ng} \cdot \mathrm{mL}^{-1}$ to a sevoflurane induction hastens slightly, approximately by $30 \%$, the occurrence of a BIS $<60$ and tracheal intubation. Unexpectedly, this effect was slight with no clear dose-effect relationship between the time to obtain the appropriate criteria for intubation and the various concentrations of alfentanil. Indeed, the addition of high opioid doses during steady state conditions reduces by approximately $50 \%$ to $80 \%$ the various MACs of sevoflurane, which should accelerate induction and tracheal intubation. For example, $3 \mathrm{ng} \cdot \mathrm{mL}^{-1}$ fentanyl reduced by $66 \%$ the MAC and by $83 \%$ the MAC-BAR of sevoflurane. ${ }^{14}$ Sevoflurane $\mathrm{ED}_{95}$ for tracheal intubation is reduced by $50 \%$ and reaches $3.2 \%$ when a $1 \mu \mathrm{g} \cdot \mathrm{kg}^{-1}$ bolus of remifentanil is associated with sevoflurane. ${ }^{9}$ While maintaining a steady state concentration of sevoflurane, the MAC for tracheal intubation is reduced by $42 \%$ when adding $\mathrm{l} \mu \mathrm{g} \cdot \mathrm{kg}^{-1}$ fentanyl. ${ }^{8}$ The maintenance of a steady state concentration of sevoflurane used in these previous studies is relevant only for maintenance of anesthesia but not for induction. In the present study, we chose a different approach, maintaining alfentanil at steady state concentrations. Indeed, during an inhalation induction, end-tidal, blood and cerebral concentrations of sevoflurane increase rapidly with, approximately, a two-minute half time to equilibrium between blood and brain. ${ }^{15}$ 
This suggests that, during a mask induction, it is probably not possible to reduce the time to tracheal intubation to less than two minutes, without a risk of awareness. This may explain why, during an inhalation induction, alfentanil cannot reduce the time to loss of consciousness. ${ }^{11}$ Alfentanil pre-treatment was, as well, unable to reduce consistently the time to obtain a BIS $<60$ probably because of this lag and because alfentanil plasma concentrations as high as $50 \mathrm{ng} \cdot \mathrm{mL}^{-1}$ have no effect on BIS during sevoflurane anesthesia. ${ }^{10}$

Errors of the pharmacokinetic model due to low target-concentrations of alfentanil may also explain the lack of a dose-effect on intubation times. Low opioid target-concentrations were chosen to preserve spontaneous ventilation because of a synergistic effect between alfentanil and sevoflurane on respiratory depression. ${ }^{10}$ Unequal mean prediction errors of alfentanil concentrations may have attenuated the dose-effect relationship. Although the Scott pharmacokinetics model performs well to predict alfentanil concentrations during maintenance, this model has not been validated during the induction of anesthesia. ${ }^{16,17}$ Unfortunately no model specific to induction is available.

Clinical interpretation of the criteria used to decide on tracheal intubation may also have influenced our results. During an inhalation induction, intubation is performed either after a fixed delay and/or according to (subjective) clinical signs such as mandible relaxation and Guedel criteria. A minimal five-minute delay is usually recommended before intubation is attempted. ${ }^{6}$ The time to allow intubation was much shorter in this study, even in patients not receiving alfentanil, probably because fixed criteria were used. These were, perhaps, insufficient to evaluate the depth of anesthesia even if they predict the success of laryngeal mask insertion with a sensitivity of $100 \% .^{1,18}$ Although this study was unblinded, the same number of attempts, as well as the same time to tracheal intubation, suggest that the criteria were followed equally in all groups. The high incidence of cough after tracheal intubation and after cuff inflation indicates that the airway remained highly reactive whatever the concentration of alfentanil. The maintenance of such a high tracheal reactivity during induction with high concentrations of sevoflurane contradicts a previous report where 1 MAC of sevoflurane was able to suppress the cough response to cuff inflation during maintenance in $30 / 32$ patients. ${ }^{19}$

Whereas beneficial on heart rate and time to allow tracheal intubation, the highest concentration of alfentanil was associated with a $50 \%$ incidence of prolonged apnea. This apnea occurred mainly after tra- cheal intubation and, fortunately, was not associated with hypoxemia. This effect of opioids is well-known but was not expected with the low doses of alfentanil used in this study (about $10 \mu \mathrm{g} \cdot \mathrm{kg}^{-1}$ alfentanil had been administered in ten minutes at the time of tracheal intubation in Group 75). Furthermore, at the highest alfentanil target-concentration, vocal cord opening was incomplete in half the cases and severe cough was observed. As a consequence, neuromuscular blockade remained necessary in three patients receiving the highest alfentanil concentration.

In summary, during $8 \%$ sevoflurane inhalation induction, a $75 \mathrm{ng} \cdot \mathrm{mL}^{-1}$ alfentanil plasma target-concentration provides better stability of heart rate and arterial pressure than lower concentrations. Time to allow tracheal intubation is shortened slightly with the 75 $\mathrm{ng} \cdot \mathrm{mL}^{-1}$ alfentanil target-concentration. However alfentanil is unable to suppress cough reflex and the incidence of apnea is increased. The use of alfentanil 75 $\mathrm{ng} \cdot \mathrm{mL}^{-1}$ may be of clinical interest in patients at risk of cardiac complications. According to the Scott pharmacokinetics model, such a target-concentration may be obtained in $1.5 \mathrm{~min}$ after a $7 \mu \mathrm{g} \cdot \mathrm{kg}^{-1}$ alfentanil infusion.

\section{References}

1 Ti LK, Chow MY, Lee TL. Comparison of sevoflurane with propofol for laryngeal mask airway insertion in adults. Anesth Analg 1999; 88: 908-12.

2 Joo HS, Perks WJ. Sevoflurane versus propofol for anesthetic induction: a meta-analysis. Anesth Analg 2000; 91: 213-9.

3 Vakkuri AP, Lindgren L, Korttila KT, Yli-Hankala $A M$. Transient hyperdynamic response associated with controlled hypocapneic hyperventilation during sevoflurane-nitrous oxide mask induction in adults. Anesth Analg 1999; 88: 1384-8.

4 Vial G, Nathan N, Benrhaiem M, Peyclit A, Feiss P. Paroxystic systemic hypertension during inhalation induction with sevoflurane 8\% (Letter). Can J Anesth 2000; 47: 191-2.

5 Hall JE, Ebert TJ, Harmer M. Induction characteristics with $3 \%$ and $8 \%$ sevoflurane in adults: an evaluation of the second stage of anaesthesia and its haemodynamic consequences. Anaesthesia 2000; 55: 545-50.

6 Muzi M, Robinson BJ, Ebert TJ, O'Brien TJ. Induction of anesthesia and tracheal intubation with sevoflurane in adults. Anesthesiology 1996; 85: 536-43.

7 Katoh T, Ikeda K. The effects of fentanyl on sevoflurane requirements for loss of consciousness and skin incision. Anesthesiology 1998; 88: 18-24.

8 Katob T, Nakajima $\Upsilon$, Moriwaki G, et al. Sevoflurane requirements for tracheal intubation with and without fentanyl. Br J Anaesth 1999; 82: 561-5. 
9 Cros AM, Lopez C, Kandel T, Sztark F. Determination of sevoflurane alveolar concentration for tracheal intubation with remifentanil, and no muscle relaxant. Anaesthesia 2000; 55: 965-9.

10 Dahan A, Nieuwenhuijs D, Olofsen E, Sarton E, Romberg R, Teppema L. Response surface modeling of alfentanil-sevoflurane interaction on cardiorespiratory control and bispectral index. Anesthesiology 2001; 94: 982-91.

11 Muzi M, Colinco MD, Robinson BJ, Ebert TJ. The effects of premedication on inhaled induction of anesthesia with sevoflurane. Anesth Analg 1997; 85: 1143-8.

12 Wang JY, Winship SM, Thomas SD, Gin T, Russel GN. Induction of anaesthesia in patients with coronary artery disease: a comparison between sevofluraneremifentanil and fentanyl-etomidate. Anaesth Intensive Care 1999; 27: 363-8.

13 Nathan N, Vial G, Benrhaiem M, Peyclit A, Feiss $P$. Induction with propofol target-concentration infusion vs. $8 \%$ sevoflurane inhalation and alfentanil in hypertensive patients. Anaesthesia 2001; 56: 251-7.

14 Katoh T, Kobayashi S, Suzuki A, Iwamoto T, Bito H, Ikeda $K$. The effect of fentanyl on sevoflurane requirements for somatic and sympathetic responses to surgical incision. Anesthesiology 1999; 90: 398-405.

15 Olofsen E, Dahan A. The dynamic relationship between end-tidal sevoflurane and isoflurane concentrations and bispectral index and spectral edge frequency of the electroencephalogram. Anesthesiology 1999; 90: 1345-53.

16 Raemer DB, Buschman A, Varvel JR, et al. The prospective use of population pharmacokinetics in a computer-driven infusion system for alfentanil. Anesthesiology 1990; 73: 66-72.

17 Barvais L, Cantraine F, D'Hollander A, Coussaert E. Predictive accuracy of continuous alfentanil infusion in volunteers: variability of different pharmacokinetic sets. Anesth Analg 1993; 77: 801-10.

18 Drage MP, Nunez J, Vaughan RS, Asai T. Jaw thrusting as a clinical test to assess the adequate depth of anaesthesia for insertion of the laryngeal mask. Anaesthesia 1996; 51: 1167-70.

19 Klock PA Jr, Czeslick EG, Klafta JM, Ovassapian A, Moss $J$. The effect of sevoflurane and desflurane on upper airway reactivity. Anesthesiology 2001; 94: 963-7. 